\title{
Predation during early post-settlement varies in importance for shaping marine sessile communities
}

\author{
Michael A. Sams*, Michael J. Keough \\ Department of Zoology, University of Melbourne, Victoria 3010, Australia
}

\begin{abstract}
Predation on newly settled sessile invertebrates is an important process shaping the structure of benthic marine communities in localised areas on the northeastern coast of North America. There are no studies that have tested whether predation acts similarly in other locations, so it is not clear whether generalisations can be made about the effects of predation on different sessile communities. In this study we determined whether predation on newly settled recruits altered the structure of 2 different sessile communities in Port Phillip Bay, Australia. We conducted a series of predator exclusion experiments using full cage, partial cage and no cage treatments at 2 study sites, Williamstown and Queenscliff. Full cage and partial cage treatments of either $1 \mathrm{~cm}$ or $2 \mathrm{~mm}$ mesh sizes were used to separate the effects of different size classes of predators. At both sites, a variety of colonial and solitary ascidians, bryozoans, sponges and polychaetes settled onto experimental surfaces. Predation had little impact on the recruitment success of taxa present at Williamstown and did not alter community structure. At Queenscliff, didemnid ascidians had higher abundances on completely caged plates ( $2 \mathrm{~mm}$ mesh) after $40 \mathrm{~d}$, suggesting that they may have been preyed upon in treatments exposed to carnivores. However, predation had no effect on the densities of other taxa found on experimental surfaces, and there were no differences in overall community structure between treatments. Recruitment rates were low and predators were never observed on experimental surfaces at Queenscliff, so predation on newly settled recruits may be an uncommon occurrence for most taxa. In contrast, predators were commonly found on experimental surfaces at Williamstown, but recruitment rates were high and predators had little effect on the abundance of newly settled prey. The results of this study show that predators can have weak effects on recent recruits and that predation during early post-settlement is not a major process shaping the structure of all marine sessile communities.
\end{abstract}

KEY WORDS: Recruitment $\cdot$ Predation $\cdot$ Ascidian $\cdot$ Bryozoan $\cdot$ Post-settlement mortality Resale or republication not permitted without written consent of the publisher

\section{INTRODUCTION}

Predation has long been recognised as an important factor controlling the structure of communities, and much of our understanding of the effects of predation on community structure stems from extensive studies on sessile marine invertebrates (see Sih at al. 1985 for review). Most of these studies have focused on adult prey animals, but adults are only one component of complex life cycles, and comparatively little is known about the community level effects of predation on early life history stages.
Two life history stages are thought to be times of very high mortality for many species. Planktonic mortality during the larval period can be high, and is notoriously difficult to estimate (see Morgan 2001 for review). Following settlement, most species are very vulnerable during and soon after metamorphosis, when they are much smaller than adults, and often have yet to form large colonies or defensive structures including calcification that greatly increase their chances of survival (e.g. Davis 1988). During early post-settlement, mortality rates are often high (Gosselin \& Quian 1997, Hunt \& Scheibling 1997). 
An important cause of early post-settlement mortality for sessile invertebrates is predation. Fish can be major predators of recently settled bryozoans (Keough \& Downes 1982) and early post-settlement and juvenile ascidians (Sutherland 1974, Keough 1984a, Keough \& Downes 1986, Hurlbut 1991, Osman \& Whitlatch 2004). Gastropods are also voracious predators of early post-settlement ascidians in communities in New England (Osman et al. 1992, Osman \& Whitlatch 1995, 1998, 2004) and the San Juan Islands, Washington, USA (Young \& Chia 1984), causing a significant reduction in their densities. However, most studies of early post-settlement mortality have largely focused on the effect of predation at the population level (e.g. Keough \& Downes 1986, Gosselin \& Qian 1996, Petraitis 1990, 1991). Other studies have not separated predation from other, less specific sources of mortality, such as trampling and bulldozing (e.g. Barkai \& Branch 1988, Zamerano et al. 1995, Duffy \& Harvelicz 2001) by mobile consumers, or have measured effects at much later stages of development, making it difficult to pinpoint whether predation occurred primarily on early post-settlement, juvenile or adult individuals (e.g. Russ 1980, Menge 1991, Moreno 1995). As a result, our knowledge of the overall impact of predation during early post-settlement is still limited.

In the most detailed study of the link between early post-settlement predation and community structure, Osman et al. (1992) and Osman \& Whitlatch (1995, 1998, 2004) found that predation had major effects on the recruitment of species into adulthood, and caused dramatic shifts in the structure of subtidal fouling communities in New England. In these communities, the small gastropods Anachis lafresnayi and Mitrella lunata prey on newly settled ascidians. Predation by these gastropods resulted in a shift of community dominance from ascidians in areas where these predators were absent or occurred in low abundance, to bryozoans in areas where these predators were present in high abundance. By controlling which species are able to recruit into communities, these small gastropods were able to facilitate the long-term persistence of competitively inferior species in localised areas, regardless of larval sources and settlement rates. Although presenting a striking example of the way in which predation on recent settlers can have a key influence in shaping the structure of communities, these studies were restricted to localised communities in northeastern America, and few other studies examining such control of community structure by predators exist. Consequently, it is not clear whether the processes shaping community structure in New England are common to all benthic communities, or whether they are unique to that region.

In this study, we determined whether predation soon after settlement influences the structure and develop- ment of 2 sessile communities in Port Phillip Bay, Australia. To test the impacts of predation, we conducted a series of predator exclusions using cages that prevented predators from accessing recently settled sessile invertebrates. We carried out 2 independent studies at 2 distinct subtidal locations in Port Phillip Bay, to determine how the effects of predation may vary between communities, and thus how general the effects of predation during early post-settlement periods may be. We also excluded predators (using 2 different mesh sizes) to separate the effects of large and small predators.

\section{MATERIALS AND METHODS}

Study site. Experiments were carried out subtidally from mid-December 2005 to late January 2006 at Workshops Pier, Williamstown (3751'40"S, $144^{\circ} 54^{\prime} 29^{\prime \prime} \mathrm{E}$ ), and from early February 2006 to mid March 2006 at Queenscliff Pier, Queenscliff, (38 16' 04" S, $\left.144^{\circ} 40^{\prime} 04^{\prime \prime} \mathrm{E}\right)$. Williamstown and Queenscliff are at the north and south ends, respectively, of Port Phillip Bay, a large $\left(2000 \mathrm{~km}^{2}\right)$ embayment in southeastern Australia. Workshops Pier has a maximum depth of 4 to $5 \mathrm{~m}$, and is well protected from the prevailing winds and current by nearby piers and jetties. The Yarra River exits into Port Phillip Bay near Williamstown, depositing large amounts of sediment into the water around Workshops Pier, creating a muddy sea floor. In contrast, Queenscliff Pier is close to Port Phillip Heads, and is more exposed, regularly experiencing moderate surge and flushing by currents bearing clean water from Bass Strait. Sediment levels in the water are low at Queenscliff, and the bottom substratum consists of coarse sand. The water depth is 3 to $4 \mathrm{~m}$.

At both sites, sessile invertebrates attach in large numbers to the wooden pylons of the piers, and there is little unoccupied space. The sessile invertebrate community at Williamstown is dominated by the solitary ascidian Pyura stolonifera, with the colonial ascidians Botryllus schlosseri and Diplosoma listerianum also occurring in high abundances. Numerous other organisms also contribute to this community, particularly colonial ascidians (Family Didemnidae), solitary ascidians (Ciona intestinalis, Ascidiella aspersa and Styela clava), arborescent bryozoans (Bugula stolonifera, B. flabellata, B. neritina and Tricellaria porteri), encrusting bryozoans (Watersipora subtorquata and Conopeum seurati), as well as barnacles (Balanus amphitrite and Elminius modestus) and serpulid polychaetes (Pomatocerus taeniatus and Hydroides elegans, amongst others). With the exception of $P$. stolonifera, $P$. taeniatus and possibly E. modestus, the 
dominant members of the fauna at Workshops Pier are exotic to the waters of Port Phillip Bay, and are relatively recent introductions (Hewitt et al. 2004).

In contrast, the invertebrate community found at Queenscliff consists mostly of native species. The Queenscliff community is not dominated by any particular species, but a range of large sponges and colonial ascidians (including a suite of didemnids, plus Amphicarpa meridiana, Clavelina cylindrica, Botrylloides perspicuus, and Sycozoa cerebreformis) occur in highest abundances. A number of other organisms also contribute significantly to community structure at Queenscliff, including solitary ascidians (Pyura gibbosa and Herdmania momus), arborescent bryozoans (Bugula dentata and Tricellaria porteri) and anemones (Anthothoe albocincta).

The peak time for the settlement of species at both Williamstown and Queenscliff occurs from late November through to early March (Power 1998). The timing of predator exclusion experiments therefore coincided with peak settlement times at both sites.

Collection of sessile recruits. In all experiments, early post-settlement individuals were collected on acrylic plastic (Plexiglas) plates $(11 \times 11 \mathrm{~cm}, 1.5 \mathrm{~cm}$ thick). Plates were roughened on the side to be exposed to settlement, and acted as hard substrata for larvae to settle onto and metamorphose.

Predator exclusions. At Williamstown, the overall aim of predator exclusion experiments was to collect an initial community of early post-settlement individuals on plates suspended from panels over a short time, and then transfer these plates to pier pylons where caging treatments were applied. For this initial collection period, plates were attached to the downwards facing surface of $80 \times 80 \mathrm{~cm}$ PVC panels suspended horizontally from a shaded part of the pier and weighted down with a brick. Fifteen plates were placed on a single panel. Panels were oriented horizontally in order to minimise sediment build up. Newly settled individuals were collected on plates set out on panels for $4 \mathrm{~d}$, which was deemed sufficient time to collect a suitable number of individuals for analysis, whilst still ensuring that organisms were very young. Plates were suspended in the water column in order to limit their exposure to benthic predators during the periods of settler collection. The purpose of this initial collection period was to determine whether particular species, known to be present on plates after initial collection periods, were removed when exposed to benthic predators. Such removal of species would suggest particularly high rates of predation.

Plates were removed from panels immediately after initial collection periods and attached to pier pylons where they could be easily accessed by any benthic predators that preyed on early post-settlement re- cruits. For each experiment, a total of 30 plates were attached to pylons (5 treatments, 6 replicates). Plates were attached only to pier pylons that reached a maximum depth of $4 \mathrm{~m}$ below the low water mark. The outermost row of pylons was not used, in order to maintain consistent physical conditions. In total, 14 pylons met these criteria and were used in experiments. All plates were randomly assigned a pylon for attachment, and then placed in a random direction around the piling and randomly assigned to depths of 1,2 , or $3 \mathrm{~m}$. The location of plates was randomized by generating random numbers corresponding to pylon number, orientation and depth.

At Queenscliff, panels could not be suspended from the pier, so we adopted a slightly different method to collect settlers and attach plates. Plates were hammered (using stainless steel nails) directly onto a sea wall located under a shaded part of the pier where they were arranged in a $6 \times 6$ array, with approximately $15 \mathrm{~cm}$ of space separating each plate from its neighbours. Plates were placed at depths between 1 and $3 \mathrm{~m}$ below the low water mark. Unlike the initial collection of recruits at Williamstown, plates at Queenscliff were exposed to benthic predators during settler collection. This should not have introduced any bias because all plates were equally exposed to benthic predators prior to caging and no predators were on plates when cages were added. Plates were left on the sea wall for $4 \mathrm{~d}$ before caging, to allow time for initial recruitment. As at Williamstown, the purpose of collecting initial recruits at Queenscliff was to determine whether the initial species composition would change after treatments were applied, suggesting high rates of predation.

In order to determine the identities and abundances of species that recruited onto plates during initial collection periods, 6 plates were removed from random locations on panels (at Williamstown) or from the sea wall (at Queenscliff) on the same day that plates were caged. These removed plates were taken to the laboratory, where recruits were identified and counted.

After the period of settler collection, the methods adopted at the 2 sites were identical. Plates were assigned to one of 5 treatments: (1) uncaged; (2) caged with $1 \times 1 \mathrm{~cm} \mathrm{mesh}$; (3) partially caged with $1 \times 1 \mathrm{~cm}$ mesh; (4) caged with $2 \times 2 \mathrm{~mm}$ mesh; (5) partially caged with $2 \times 2 \mathrm{~mm}$ mesh.

Each treatment consisted of 6 replicates. Uncaged treatments exposed newly settled individuals on plates to all potential predators, whilst caged treatments excluded predators from individuals on plates. The identity of predators was not known at the outset of these experiments, so 2 different mesh sizes were used to establish whether different size classes of predators have different effects on the survivorship of recently 
settled sessile invertebrates. Cages of $1 \times 1 \mathrm{~cm}$ mesh were intended to keep larger predators, such as fish, sea-stars and large gastropods from plates. Cages of 2 $\times 2 \mathrm{~mm}$ mesh were used to exclude virtually all predators, including small/juvenile fish and small invertebrates, from plates. The predators found to be important for early post-settlement individuals in New England would be excluded by $2 \times 2 \mathrm{~mm}$ mesh. Partially caged treatments acted as caging (procedural) controls, giving predators access to newly settled individuals whilst still modifying flow and light levels in a way similar to complete cages.

Cages of $1 \times 1 \mathrm{~cm}$ mesh were built from plastic Gutter Guard ${ }^{\mathrm{TM}}$ mesh that was held together tightly with plastic cable ties. Cages of $2 \times 2 \mathrm{~mm}$ mesh were built using a frame of plastic Gutter Guard ${ }^{\mathrm{TM}}$ mesh with the roof and walls removed. The entire frame was then given a roof and side walls made of $2 \times 2 \mathrm{~mm}$ fibreglass fly screen mesh that was attached and sealed tightly around the frame using plastic cable ties. All cages had the same dimensions, with a height of $15 \mathrm{~cm}$ and sides with lengths of $13 \mathrm{~cm}$. Partial cages had half of the roof and half of 2 side walls removed to give predators sufficient access to plates, whilst leaving as much of the cage intact as possible. This was deemed sufficient area to allow most potential predators access to plates and adult fish up to $12 \mathrm{~cm}$ in size were seen entering and exiting partial cages at Williamstown. Similarly, the large sea star Coscinasterias muricata was seen moving through partial cages set up at Queenscliff. Some large fish and invertebrates may still have been excluded from plates by partial cages, but such predators were absent or rare at both sites and it seems unlikely that they would be important predators on newly settled sessile invertebrates in these communities. Cages were held in place over plates by hammering galvanised decking staples through side flaps at the bottom of each cage and into the sea wall/pier pylons. The side walls and roofs of cages did not touch plates.

Predator exclusion experiments were repeated for different lengths of time at both sites in order to (1) determine the effect that different levels of exposure to predation through time might have on early post-settlement mortality, and (2) monitor changes in community structure as the communities on plates developed and aged. At Williamstown, predator exclusions were run for 3, 15 and $35 \mathrm{~d}$ (not including the $4 \mathrm{~d}$ settler collection period). Settlement rates at Queenscliff were much lower than at Williamstown. Due to this, a 3 d experiment at Queenscliff was unsuccessful, because recruitment was too low for analysis within this time. At Queenscliff, 20 and 40 d caging experiments were carried out in order to ensure that enough animals were present on plates for analysis. Experi- ments were monitored every 2 to $4 \mathrm{~d}$ for between 1 to 3 $\mathrm{h}$, to check that cages were intact, and to try and observe any animals feeding on plates.

Importantly, cages may inhibit the settlement of larvae onto plates and cause differences in recruitment between treatments that could potentially disguise the effects of predation. Prior to the outset of predator exclusion experiments, the effects of caging on the settlement of key species were measured in 3 separate experiments. Caging had no effect on the settlement of all species measured, except for barnacles, which settled in higher abundances on uncaged plates than on caged plates (Sams 2006). Due to this artefact, the recruitment rates of barnacles are not presented here.

Data collection and analysis. At the end of each experiment plates were removed, placed into plastic snap lock bags to capture any mobile organisms active on plates, taken back to the laboratory and stored in running filtered seawater. The organisms found on each plate were identified to the lowest taxonomic level possible, and their densities were determined by counting under a dissecting microscope all individuals on the plate. For the $35 \mathrm{~d}$ experiment at Williamstown, the surface areas of plates occupied by colonial organisms were also estimated as percentage covers. This was done by placing a grid of 100 evenly spaced points over a plate and recording species underneath each point. Individuals occurring within $5 \mathrm{~mm}$ of the edge were not counted, because of possible edge effects.

The communities at Queenscliff and Williamstown were very different from each other, with almost no overlap in species composition on pier pilings. The experiments conducted at each of the sites were not designed for direct statistical comparisons, but rather to determine how predation during early post settlement affects distinct assemblages. As a result, no formal statistical comparisons were made between experiments carried out at the 2 sites. Similarly, experiments that were run for different lengths of time at the same site were not formally compared, because they were exposed to very different levels of larval settlement. The mean densities and percentage covers of individual species were compared between treatments within each experiment using 1-way ANOVA. Where results were significant, the pairwise differences between groups were determined using Tukey's HSD test. Transforming data did not increase homogeneity of variance, so raw data were used for all experiments. Power analyses were performed for each species where results were non-significant. An $80 \%$ difference in abundances between caged and uncaged/partially caged treatments was used as the effect size in these calculations. This effect size is representative of a large difference in recruitment due to predation and likely to cause a corresponding change in community structure, 
but is much smaller than changes in abundance caused by predators in New England (Osman \& Whitlatch, 1995, 1998, 2004). In experiments where replicates were lost, power was calculated for the average number of replicates per treatment. Overall, no replicates were lost from experiments at Queenscliff. Two replicates were lost from $3 \mathrm{~d}$ predator exclusion experiments at Williamstown (1 uncaged plate and 1 plate partially caged with $1 \times 1 \mathrm{~cm}$ mesh), 5 replicates were lost from $15 \mathrm{~d}$ experiments ( 2 uncaged plates, 2 plates caged with $1 \times 1 \mathrm{~cm}$ mesh, and 1 plate caged with $2 \times 2 \mathrm{~mm}$ mesh); 2 replicates were lost from 35 d experiments ( 2 plates partially caged with a mesh size of $1 \times 1 \mathrm{~cm}$ ).

\section{RESULTS}

\section{Williamstown}

Initial collection of recruits

For all 3 experiments conducted at Williamstown, the colonial ascidians Botryllus schlosseri, Diplosoma listerianum and didemnids were present in moderate abundances on experimental plates after the initial collection of recruits. Other species were rare or absent at the end of the initial collection period, but recruited onto plates while experiments were running. For all experiments, serpulid polychaetes were numerically dominant on plates at the end of this initial collection period, but occupied little space compared to ascidians. The abundances of these initial recruits are included in plots of predator exclusion results in the category 'initial'.

\section{Observations of potential predators}

At Williamstown, a number of small predators were active on plates. In particular, the nudibranchs Goniodoris meracula and Polycera hedgpethi were common on uncaged and partially caged plates, with densities of 2 to 10 ind. plate ${ }^{-1}$ on $35 \mathrm{~d}$ uncaged plates. Two individuals, tentatively identified as the nudibranch Thecacera pennigera, were also found on plates. The nudibranchs were more common on $15 \mathrm{~d}$ and $35 \mathrm{~d}$ plates, and were rarely observed on $3 \mathrm{~d}$ plates. Some individuals of $P$. hedgpethi were observed feeding on newly settled Bugula recruits, but most individuals were found on older, bushy colonies. G. meracula was observed feeding on the colonial ascidian Botryllus schlosseri on a number of occasions. G. meracula individuals were consistently found on larger colonies and never seen feeding on newly settled recruits. This species did little damage to colonies and appeared to have low consumption rates.
Predator exclusions

Three-day experiment. Communities on $3 \mathrm{~d}$ plates included the colonial ascidians Botryllus schlosseri, Diplosoma listerianum and didemnids, which occurred in moderate (20 to 100 ind. plate ${ }^{-1}$ ) to high densities (>100 ind. plate ${ }^{-1}$ ), whilst the solitary ascidians Pyura stolonifera and Ciona intestinalis occurred at low densities $\left(<20\right.$ ind. plate $^{-1}$; Fig. 1). Serpulid polychaetes were by far the numerically dominant group, recruiting in extremely high densities (Fig. 1), but occupying little space. The arborescent bryozoans Tricellaria porteri, Bugula stolonifera, B. neritina and the encrusting bryozoans Watersipora subtorquata and Conopeum seurati were present at low densities (Fig. 2). Very early recruits of $B$. stolonifera and $B$. flabellata were also present at low densities (Fig. 2). Ancestrulae of these species are difficult to distinguish consistently and were pooled as Bugula recruits for analysis.

Overall, predation had little effect on the structure of $3 \mathrm{~d}$ communities. The densities of Diplosoma listerianum, Pyura stolonifera, and didemnids were not significantly different between treatments, nor were there significant differences in the densities of any of the bryozoans or serpulid polychaetes between uncaged, partially caged or completely caged plates (Table 1).

The power to detect an $80 \%$ change in density between treatments was high for Diplosoma listerianum, didemnids, Pyura stolonifera, Tricellaria porteri and serpulid polychaetes (>0.8; Table 1$)$, moderate for several bryozoan (Bugula recruits, B. stolonifera, Conopeum seurati, Watersipora subtorquata: 0.3 to 0.8 ; Table 1) and low for B. neritina (<0.3; Table 1).

In contrast, the densities of 2 other common species varied between treatments. Botryllus schlosseri was twice as abundant on uncaged plates as on partially caged and completely caged plates (Table 1, Fig. 1). Ciona intestinalis was also approximately 2 to 3 times more abundant on uncaged plates than it was on partially and completely caged plates (Table 1, Fig. 1). However, these differences in densities were not consistent with patterns that would be expected to arise from the exclusion of predators (i.e. promotion of higher densities of target species in caged than in uncaged and partially caged treatments).

Fifteen-day experiment. Communities on $15 \mathrm{~d}$ predator exclusion plates were dominated by the colonial ascidians Botryllus schlosseri, Diplosoma listerianum and a didemnid species. These species settled in moderate to high densities (Fig. 3), and occupied the most space of any taxon. The solitary ascidian Pyura stolonifera occurred in slightly higher numbers than it did in $3 \mathrm{~d}$ experiments, whilst the solitary ascidian Ascidiella aspersa recruited in low 

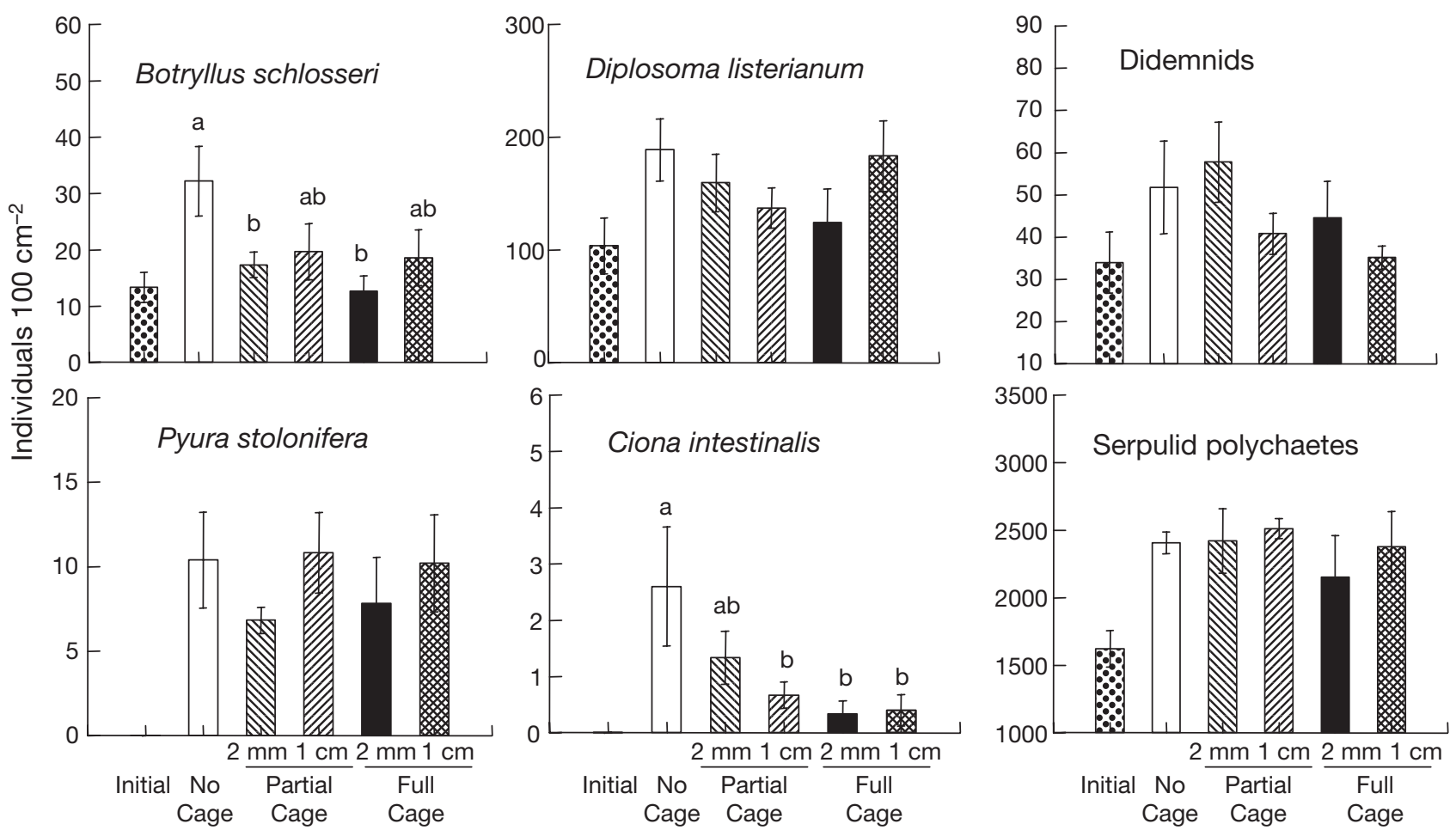

Fig. 1. Mean densities $( \pm \mathrm{SE})$ of ascidians and serpulid polychaetes at the end of $3 \mathrm{~d}$ predator exclusion experiments at Williamstown. 'Initial' represents the densities of taxa at the start of predator exclusion experiments, whilst the other 5 bars display results at the end of experiments for respective treatments. Letters occur where taxa showed significant changes in abundance between treatments (1-way ANOVA, $\mathrm{p}<0.05)$. In these cases, treatments without letters in common are significantly different from each other (Tukey's HSD, $\mathrm{p} \leq 0.05$ ). Where there is no lettering above bars, treatment means are not significantly different (1-way ANOVA, $\mathrm{p}>0.05)$

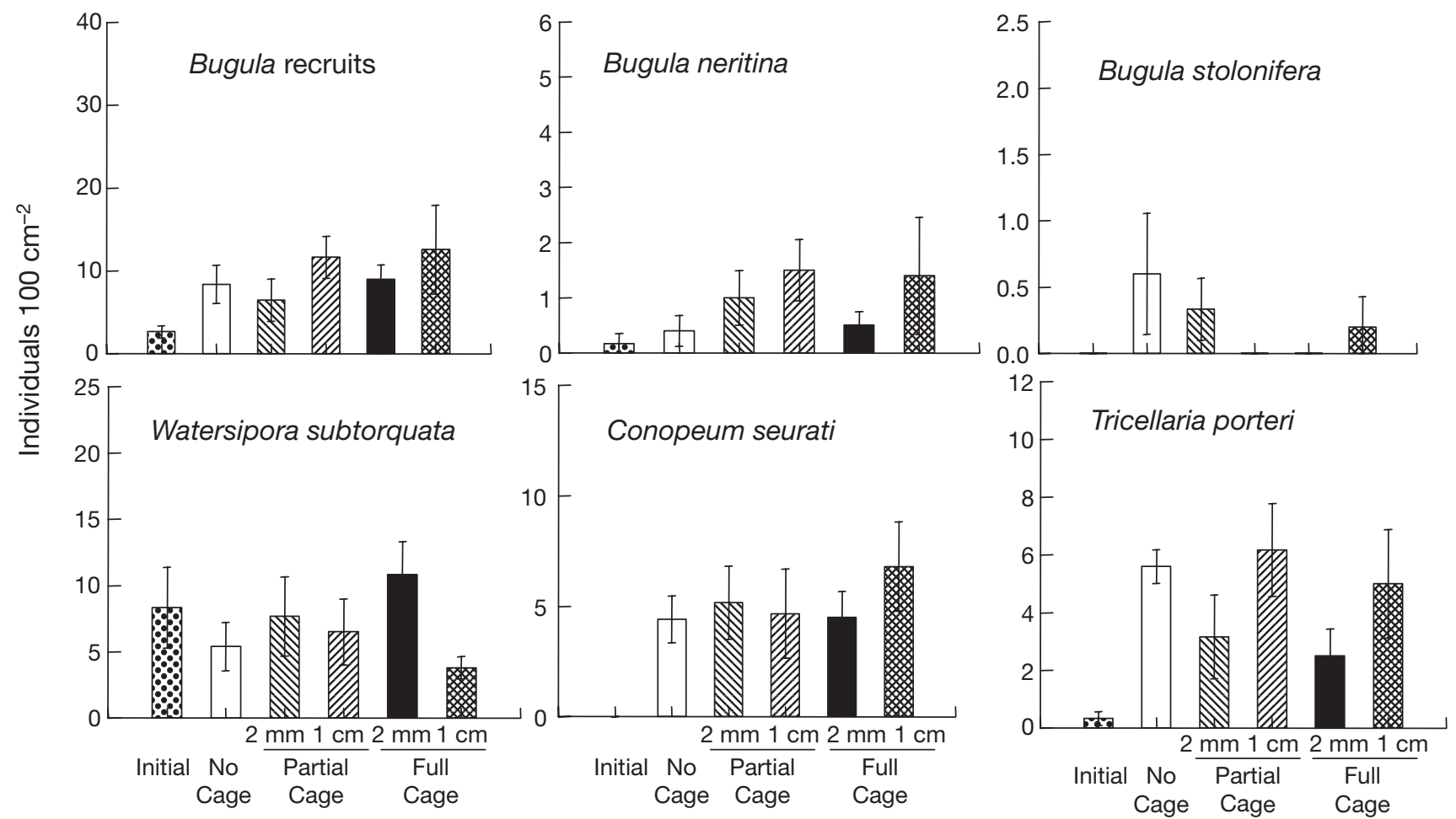

Fig. 2. Mean densities $( \pm \mathrm{SE})$ of bryozoans at the end of 3 d predator exclusion experiments at Williamstown. See legend to Fig. 1 for complete details 
Table 1. 1-way ANOVA comparing the densities of common taxa across different caging treatments at the end of 3 and $15 \mathrm{~d}$ predator exclusion experiments at Williamstown. The summaries show the p-value and residual df for each taxon. The statistical power of these experiments to detect a significant change in abundance was calculated for an effect size of $80 \%$ between uncaged/partially caged and caged treatments. na: species to which power analysis was not applicable; -: species not present.

Boldface values are significant at $\mathrm{p}<0.05$

\begin{tabular}{|c|c|c|c|c|c|c|}
\hline \multirow{2}{*}{ Taxon } & \multicolumn{3}{|c|}{$-3 \mathrm{~d}$ experiment } & & \multirow{2}{*}{$\begin{array}{c}15 \mathrm{~d} \text { experiment } \\
\text { Residual } \\
\text { df }\end{array}$} & \multirow[b]{2}{*}{ Power } \\
\hline & $\mathrm{p}$ & $\begin{array}{l}\text { Residual } \\
\text { df }\end{array}$ & Power & $\mathrm{p}$ & & \\
\hline Botryllus schlosseri & 0.024 & 27 & na & 0.061 & 29 & 0.858 \\
\hline Diplosoma listerianum & 0.270 & 27 & 0.999 & 0.596 & 29 & 0.804 \\
\hline Didemnids & 0.222 & 27 & 0.999 & 0.945 & 29 & 0.422 \\
\hline Ciona intestinalis & 0.013 & 27 & na & - & - & - \\
\hline Pyura stolonifera & 0.589 & 27 & 0.916 & 0.613 & 29 & 0.608 \\
\hline Ascidiella aspersa & - & - & - & 0.486 & 29 & 0.080 \\
\hline Tricellaria porteri & 0.178 & 27 & 0.872 & 0.501 & 29 & 0.094 \\
\hline Bugula recruits & 0.500 & 27 & 0.525 & 0.013 & 29 & na \\
\hline Bugula neritina & 0.449 & 27 & 0.072 & 0.010 & 29 & na \\
\hline Bugula stolonifera & 0.238 & 27 & 0.469 & 0.001 & 29 & na \\
\hline Bugula flabellata & - & & & 0.136 & 29 & 0.869 \\
\hline Watersipora subtorquata & 0.221 & 27 & 0.366 & 0.011 & 29 & na \\
\hline Conopeum seurati & 0.796 & 27 & 0.447 & - & - & - \\
\hline Purple sponge & - & - & - & 0.895 & 29 & 0.320 \\
\hline Serpulid polychaetes & 0.737 & 27 & 0.999 & 0.650 & 29 & 0.976 \\
\hline
\end{tabular}

numbers (Fig. 3). Ciona intestinalis was entirely absent from the community. Serpulid polychaetes were again numerically (but not spatially) dominant, although they recruited in much lower numbers than during $3 \mathrm{~d}$ predator exclusions (Fig. 3). Also appearing in $15 \mathrm{~d}$ communities was a species of purple sponge that recruited at low densities (Fig. 4). A number of bryozoan species occurred in low densities, including the encrusting Watersipora subtorquata and the arborescent Tricellaria porteri, Bugula recruits, B. stolonifera, B. flabellata and B. neritina (Fig. 4).
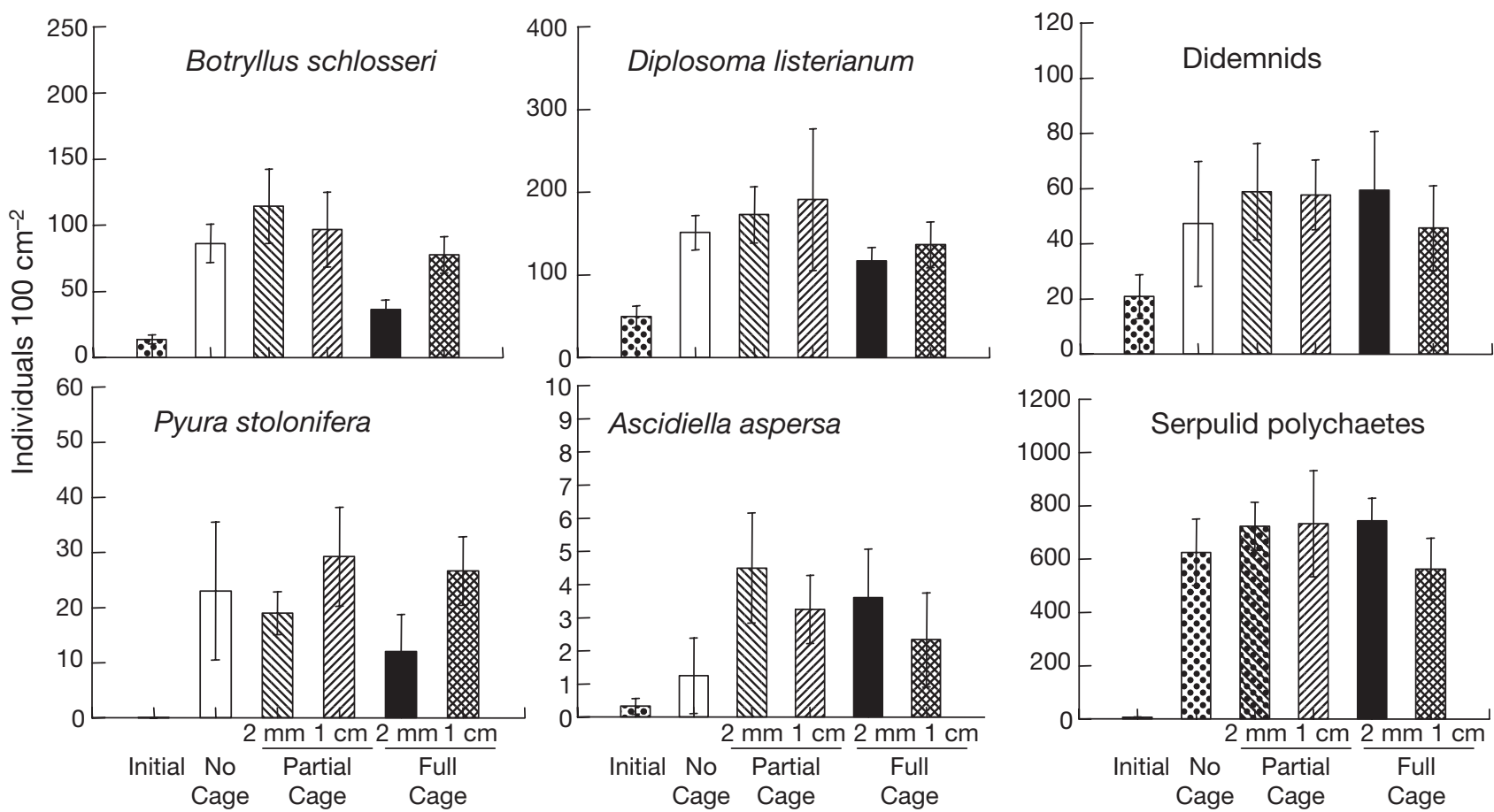

Fig. 3. Mean densities $( \pm \mathrm{SE})$ of ascidians and serpulid polychaetes at the end of $15 \mathrm{~d}$ predator exclusion experiments at Williamstown. See legend to Fig. 1 for complete details 


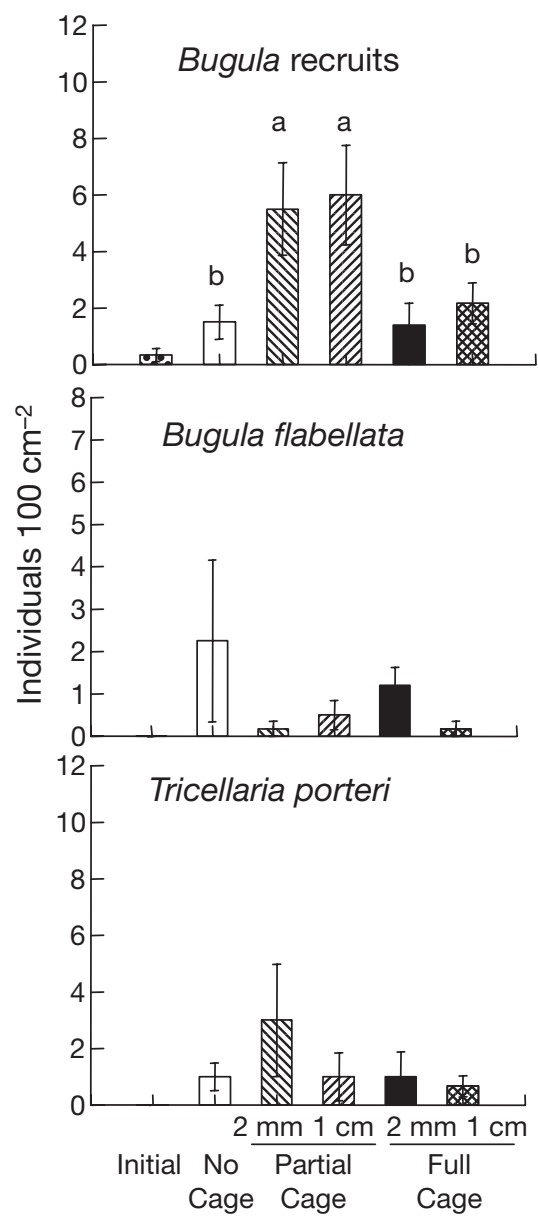

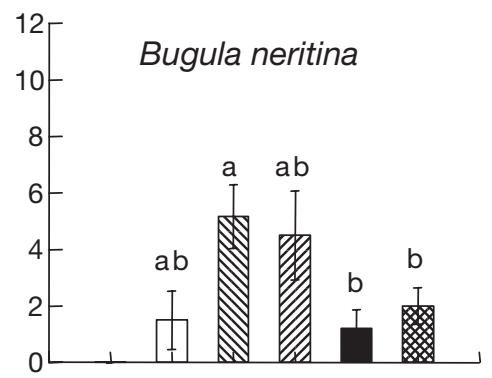

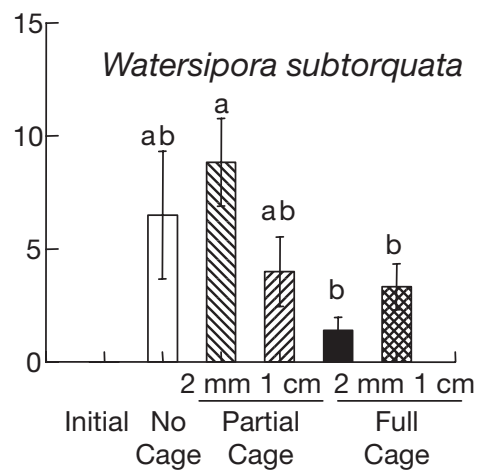

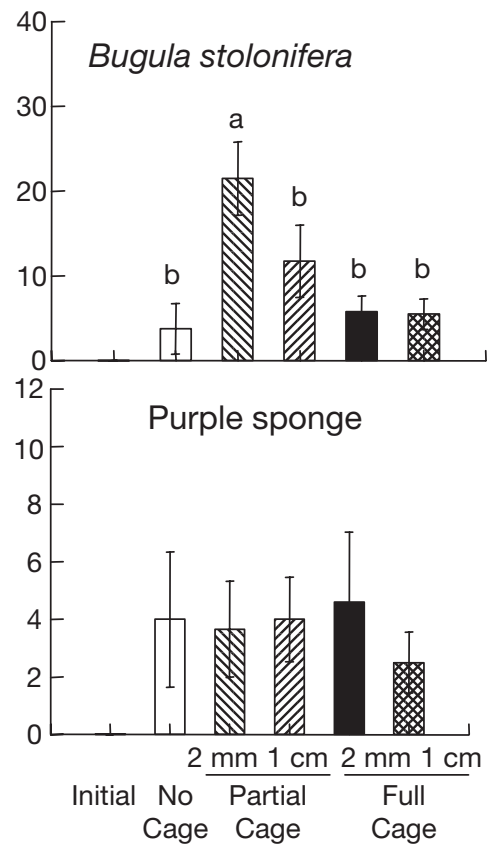

Fig. 4. Mean densities $( \pm \mathrm{SE})$ of bryozoans and purple sponge recruits at the end of $15 \mathrm{~d}$ predator exclusion experiments at Williamstown. See legend to

Fig. 1 for complete details

Predation also had little effect on the structure of communities and the densities of a number of species were again similar between treatments. There was no significant difference in the densities of Botryllus schlosseri, Diplosoma listerianum, didemnids, Pyura stolonifera, Ascidiella aspersa or for Tricellaria porteri, Bugula flabellata, serpulid polychaetes and purple sponges between treatments (Table 1).

Power was high for Botryllus schlosseri, Diplosoma listerianum, Bugula flabellata and serpulid polychaetes (>0.8; Table 1), moderate for didemnids and Pyura stolonifera (between 0.3 and 0.8; Table 1), but low for Ascidiella aspersa and Tricellaria porteri $(<0.3$; Table 1$)$.

In contrast, the densities of Bugula recruits, B. stolonifera and $B$. neritina were 2 to 3 times higher on partially caged plates than they were on uncaged and caged plates (Table 1, Fig. 4). The encrusting bryozoan Watersipora subtorquata also showed a change in density between treatments, with an approximately 50 to $75 \%$ reduction in the number of individuals on plates that were caged with $2 \mathrm{~mm}$ mesh (Table 1, Fig. 4). These differences in density were again not consistent with patterns that would be expected to result from the exclusion of predators. Most of the arborescent bryozoan taxa had similar densities on uncaged and completely caged plates.

Thirty five-day experiment. After 35 d, communities were still dominated by the colonial ascidians Botryllus schlosseri, Diplosoma listerianum, and didemnids, with many colonies (Fig. 5) and considerable occupation of space (Fig. 6). Pyura stolonifera was again the most abundant solitary ascidian contributing to community structure, whilst Ciona intestinalis, Ascidiella aspersa and Styela clava occurred in low numbers (Fig. 5). Serpulid polychaetes were again numerically dominant (Fig. 5), but only occupied $10 \%$ of space (Fig. 6). Purple sponge recruits, the arborescent bryozoans Tricellaria porteri, Bugula recruits, B. stolonifera, B. neritina, B. flabellata, and the encrusting bryozoan Watersipora subtorquata all occurred at low densities (Figs. 5 \& 7). B. stolonifera and $T$. porteri occupied approximately 1 to $8 \%$ and 2 to $10 \%$ of space, respectively (Fig. 6). There was considerable recruitment and growth of most taxa through the experiment.

Predation had little impact on the structure of $35 \mathrm{~d}$ communities, and the densities of almost all taxa in 

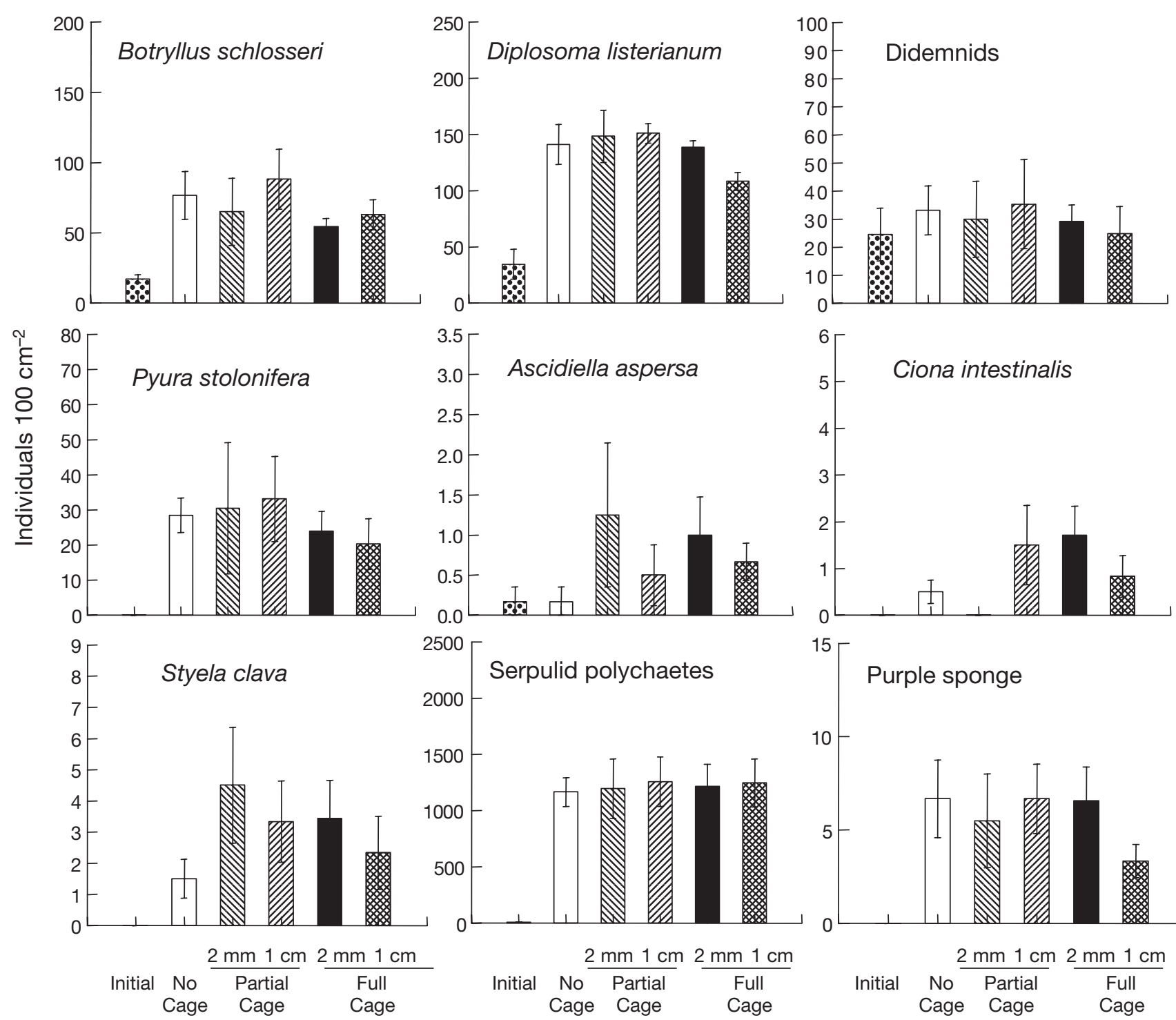

Fig. 5. Mean densities ( \pm SE) of ascidians, serpulid polychaetes, and purple sponge recruits at the end of $35 \mathrm{~d}$ predator exclusion experiments at Williamstown. See legend to Fig. 1 for complete details

areas where potential predators were excluded were similar to areas where they could access prey. There were no significant differences in the densities of the ascidians Botryllus schlosseri, Diplosoma listerianum, didemnids, Pyura stolonifera, Ciona intestinalis, Ascidiella aspersa and Styela clava between treatments, nor were there significant differences in the densities of Bugula recruits, B. neritina, B. stolonifera, B. flabellata, Watersipora subtorquata, serpulid polychaetes or purple sponges between uncaged, partially caged or completely caged, plates (Table 2).

Power was high for Botryllus schlosseri, Diplosoma listerianum, Watersipora subtorquata and serpulid polychaetes (>0.8, Table 2 ), moderate for didemnids,
Pyura stolonifera and purple sponge recruits (between 0.3 and 0.8 ; Table 2) and low for Ciona intestinalis, Ascidiella aspersa, Styela clava, Bugula recruits, B. neritina, B. flabellata and B. stolonifera $(<0.2$; Table 2$)$.

The percent covers of Diplosoma listerianum, Botryllus schlosseri, didemnids, Bugula stolonifera, Watersipora subtorquata and serpulid polychaetes were also not significantly different among uncaged, partially caged, or completely caged plates (Table 2), and the power to detect changes in percent cover was high for D. listerianum, B. schlosseri, didemnids, and serpulid polychaetes, but low for $W$. subtorquata and B. stolonifera $(<0.2$; Table 2). 


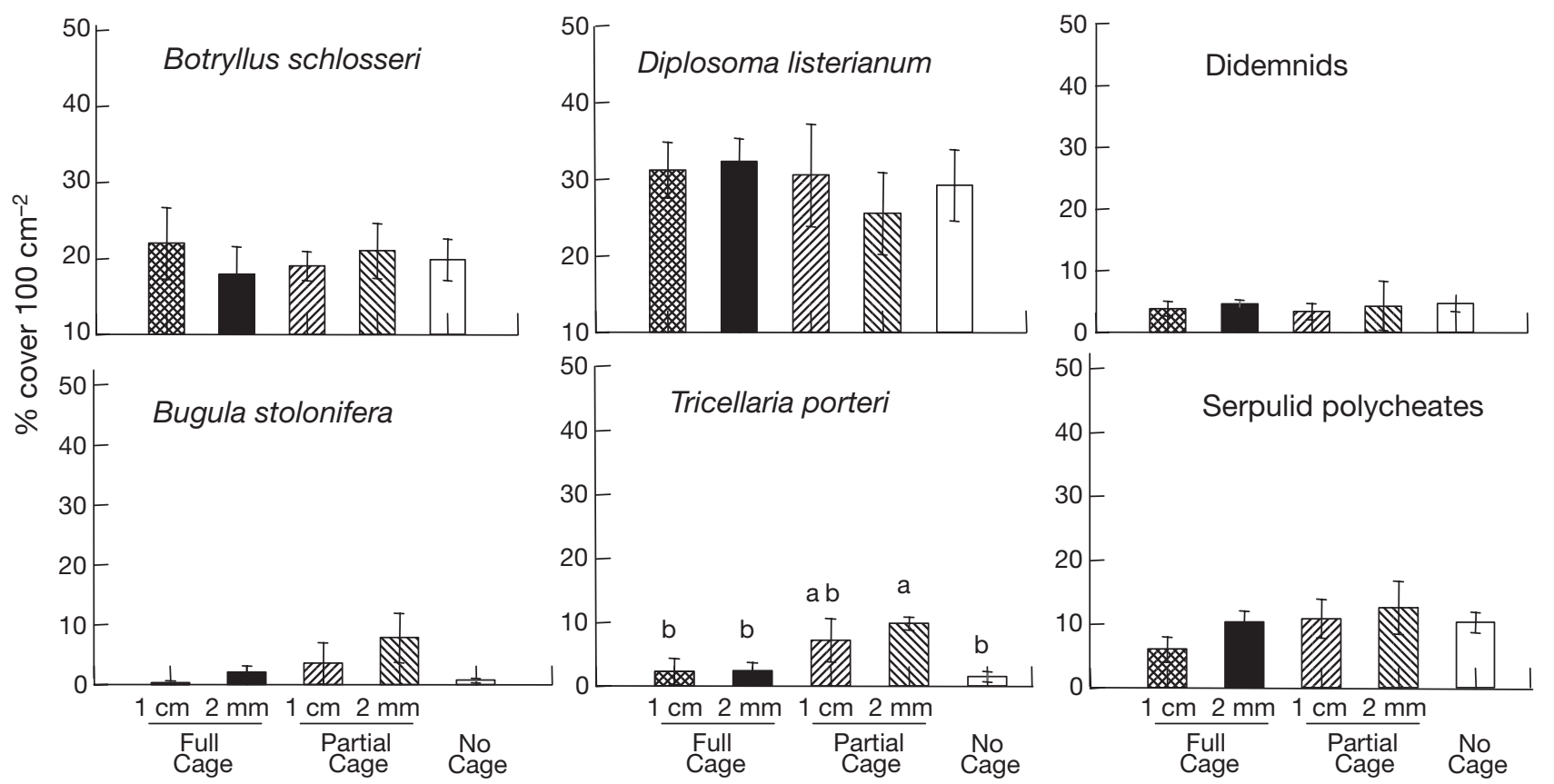

Fig. 6. Mean \% cover $( \pm \mathrm{SE})$ of dominant space occupiers on plates after 35 d predator exclusion experiments at Williamstown. See legend to Fig. 1 for complete details
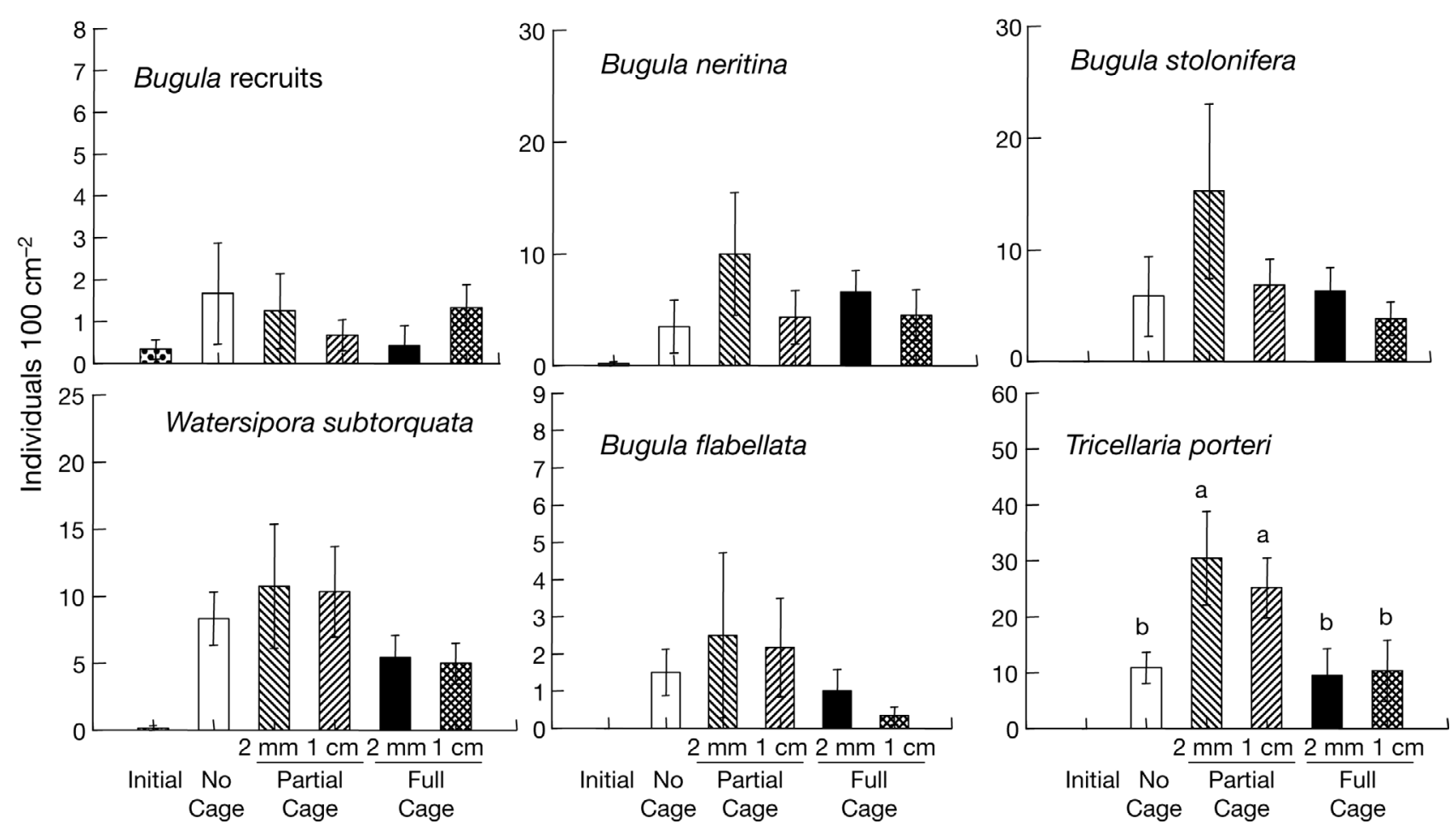

Fig. 7. Mean densities $( \pm \mathrm{SE})$ of bryozoans at the end of $35 \mathrm{~d}$ predator exclusion experiments at Williamstown. See legend to Fig. 1 for complete details

One species, the arborescent bryozoan Tricellaria porteri, was 3 times more common on plates that were partially caged with a $2 \mathrm{~mm}$ mesh than on plates in other treatments (Table 2, Fig. 7). T. porteri also had
$8 \%$ higher cover on these partially caged plates (Table 2, Fig. 6). Again, these differences in density and cover were not consistent with an effect of predator exclusion. 
Table 2. 1-way ANOVA comparing the densities and percent cover of common taxa across different caging treatments in $35 \mathrm{~d}$ predator exclusion experiments at Williamstown. The summaries show the p-value and residual df for each taxon. The statistical power of these experiments to detect a significant difference in densities and percent cover between treatments was calculated for an effect size of $80 \%$ between uncaged/partially caged and caged treatments. na: species to which power analysis was not applicable; -: species not present. Boldface values are significant at $\mathrm{p}<0.05$

\begin{tabular}{|c|c|c|c|c|c|c|}
\hline \multirow{2}{*}{ Taxon } & \multicolumn{3}{|c|}{ Density } & \multicolumn{3}{|c|}{$\%$ Cover } \\
\hline & $\mathrm{p}$ & $\begin{array}{c}\text { Residual } \\
\text { df }\end{array}$ & Power & $\mathrm{p}$ & $\begin{array}{l}\text { Residual } \\
\text { df }\end{array}$ & Power \\
\hline Botryllus schlosseri & 0.447 & 28 & 0.963 & 0.890 & 28 & 0.990 \\
\hline Diplosoma listerianum & 0.077 & 28 & 0.999 & 0.865 & 28 & 0.998 \\
\hline Didemnids & 0.947 & 28 & 0.598 & 0.952 & 28 & 1.00 \\
\hline Ciona intestinalis & 0.176 & 28 & 0.083 & - & - & - \\
\hline Pyura stolonifera & 0.812 & 28 & 0.598 & - & - & - \\
\hline Ascidiella aspersa & 0.373 & 28 & 0.056 & - & - & - \\
\hline Styela clava & 0.442 & 28 & 0.099 & - & - & - \\
\hline Tricellaria porteri & 0.013 & 28 & na & 0.023 & 28 & na \\
\hline Bugula recruits & 0.636 & 28 & 0.181 & - & - & - \\
\hline Bugula neritina & 0.443 & 28 & 0.133 & - & - & - \\
\hline Bugula flabellata & 0.468 & 28 & 0.169 & - & - & - \\
\hline Bugula stolonifera & 0.171 & 28 & 0.171 & 0.118 & 28 & 0.054 \\
\hline Watersipora subtorquata & 0.325 & 28 & 0.999 & 0.191 & 28 & 0.093 \\
\hline Purple sponge & 0.539 & 28 & 0.756 & - & - & - \\
\hline Serpulid polychaetes & 0.884 & 28 & 0.999 & 0.342 & 28 & 0.880 \\
\hline
\end{tabular}

\section{Queenscliff}

Initial collection of recruits

In contrast to Williamstown, recruitment onto experimental plates was low throughout experiments at Queenscliff. A number of the more common colonial and solitary ascidians, bryozoans and anemones found at Queenscliff did not recruit during experiments. After the initial seeding of plates, only 3 ind. of Tricellaria porteri, 1 didemnid, 2 serpulid polychaetes and 60 spirorbid polychaetes were present on sampled plates at the start of $20 \mathrm{~d}$ predator exclusion experiments. Only 1 ind. of $T$. porteri and 2 yellow sponge recruits were present on sample plates at the start of the $40 \mathrm{~d}$ predator exclusion experiment. Because the densities of recruits were so low at the end of the initial collection period, they are not included in plots.

\section{Predator exclusions}

Twenty-day experiment. At the end of the $20 \mathrm{~d}$ experiments, communities comprised a range of taxa that generally occurred in low densities. Didemnids were the most common colonial ascidians found on plates, along with Botryllus schlosseri and early recruits of Amphicarpa meridiana (Fig. 8). Early recruits of solitary ascidians were also present (Fig. 8). Spirorbid polychaetes were by far the numerically dominant species present in 20 d communities (Fig. 9), but they occupied little space. A number of other taxa also occurred in consistent but low densities, including serpulid polychaetes, the arborescent bryozoan Tricellaria porteri, the encrusting bryozoan Parasmittina raigii, a species of yellow sponge and a species of sand-encrusted sponge (Fig. 9).

The exclusion of predators had little effect on the structure of $20 \mathrm{~d}$ communities at Queenscliff, with no significant difference among treatments in the density of any species (Table 3$)$. Power was low $(<0.8$; Table 3 ) for all species, except for the sand-encrusted sponge data, which had high power ( $>0.8$; Table 3$)$.

Forty-day experiment. Communities on $40 \mathrm{~d}$ plates were essentially the same as $20 \mathrm{~d}$ communities, comprising the same suite of taxa occurring in slightly higher densities (Figs. 10 \& 11). Spirorbid polychaetes were less common than in $20 \mathrm{~d}$ experiments, but were still the numerically dominant taxa (Fig. 11).

The exclusion of predators had little effect on the structure of $40 \mathrm{~d}$ old communities, with most species unaffected (Table 3), except for didemnid ascidians, which were 4 to 6 times less common on uncaged and partially caged plates with a $1 \mathrm{~cm}$ mesh than on completely caged plates and plates partially caged with a $2 \mathrm{~mm}$ mesh (Table 3, Fig. 10). These differences in density suggest that didemnid recruits may have been preyed upon. Power was low $(<0.8$; Table 3$)$ for all species at the end of $40 \mathrm{~d}$ experiments.

\section{DISCUSSION}

We have provided experimental evidence that predation soon after settlement is not a major process shaping the structure of all marine sessile invertebrate 

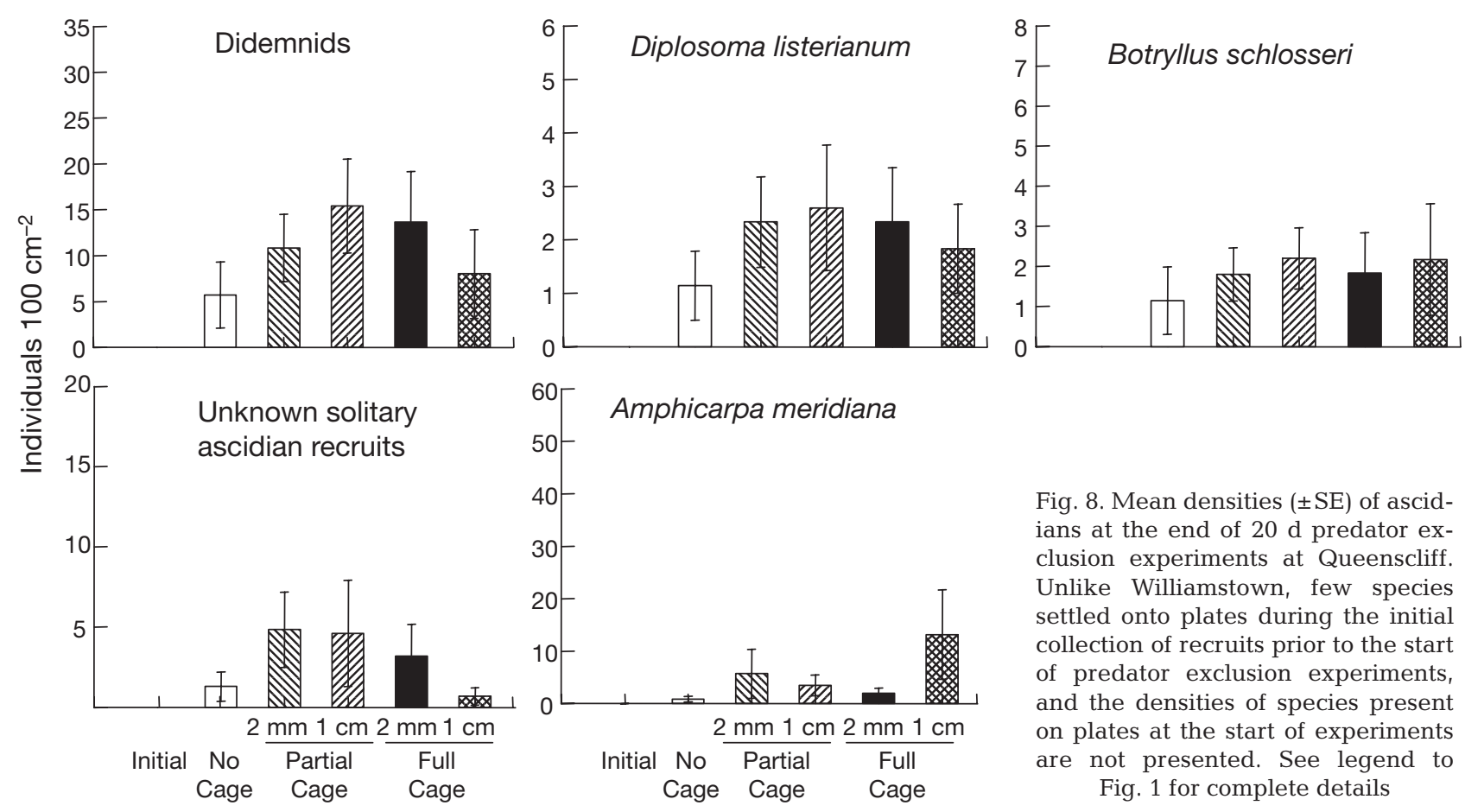

Fig. 8. Mean densities ( \pm SE) of ascidians at the end of $20 \mathrm{~d}$ predator exclusion experiments at Queenscliff. Unlike Williamstown, few species settled onto plates during the initial collection of recruits prior to the start of predator exclusion experiments, and the densities of species present on plates at the start of experiments are not presented. See legend to Fig. 1 for complete details
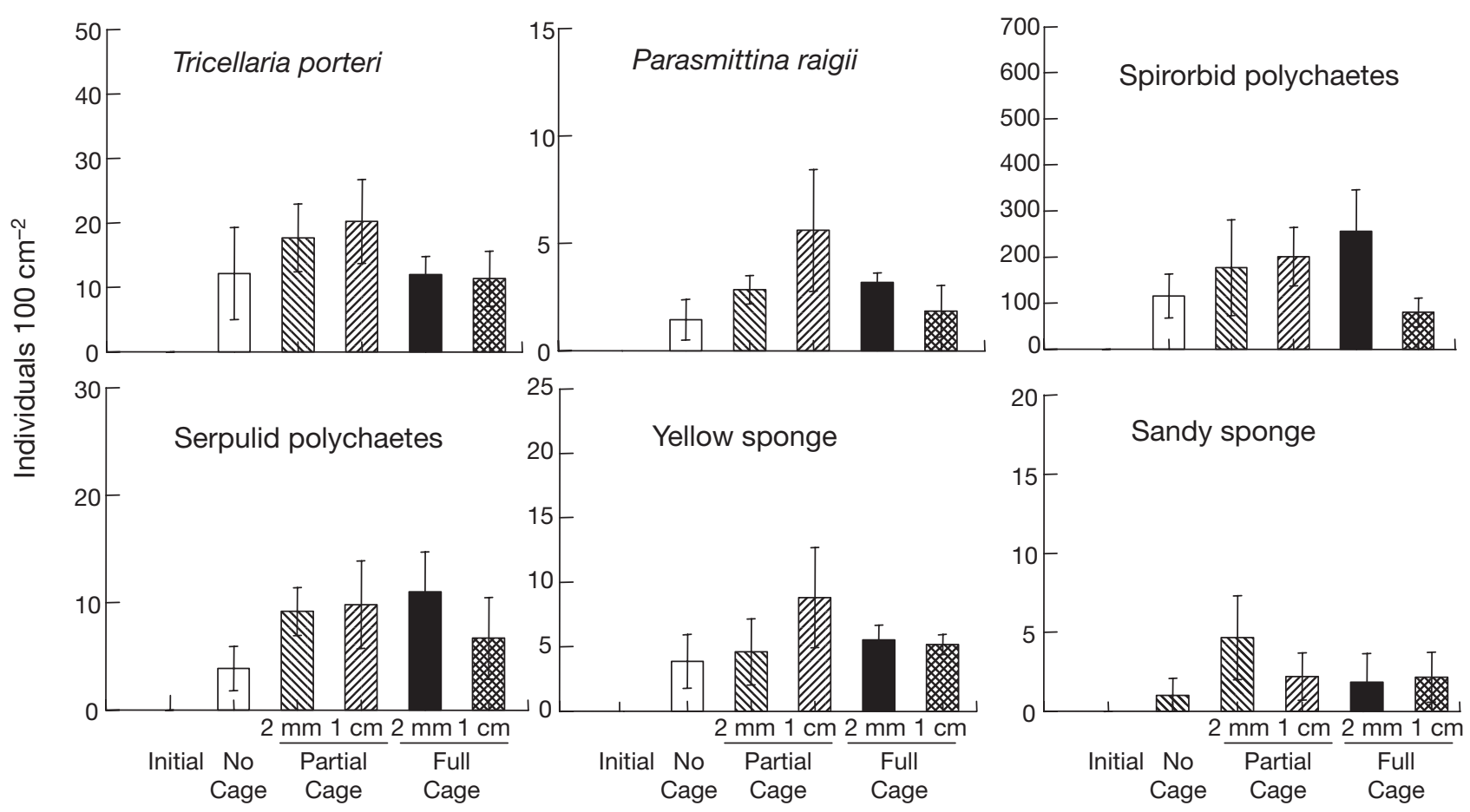

Fig. 9. Mean densities $( \pm \mathrm{SE}$ ) of other common taxa present on plates at the end of $20 \mathrm{~d}$ predator exclusion experiments at Queenscliff. See legend to Fig. 1 for complete details

communities. Overwhelmingly, the densities of species recruiting into communities at Williamstown and Queenscliff were unaffected by predation. When species did show significant differences in densities between experimental treatments, these differences were generally not consistent with patterns resulting from predation, and did not show any clear or consistent trends.

At Queenscliff, didemnids showed changes in densities between predator exclusion treatments consistent 
Table 3. 1-way ANOVA comparing the densities of common taxa across different caging treatments for 20 and $40 \mathrm{~d}$ predator exclusion experiments at Queensciff. The summaries show the p-value and residual df for each taxon. The statistical power of these experiments to detect a significant difference in abundance between treatments was calculated for an effect size of $80 \%$ between uncaged/partially caged and caged treatments. na: species to which power analysis was not applicable.

Boldface values are significant at $\mathrm{p}<0.05$

\begin{tabular}{|c|c|c|c|c|c|c|}
\hline \multirow[b]{2}{*}{ Taxon } & \multicolumn{3}{|c|}{ _ 20 dexneriment } & \multirow[b]{2}{*}{$\mathrm{p}$} & \multirow{2}{*}{$\begin{array}{l}0 \text { d experiment } \\
\text { Residual } \\
\text { df }\end{array}$} & \multirow[b]{2}{*}{ Power } \\
\hline & $\mathrm{p}$ & $\begin{array}{l}\text { Residual } \\
\text { df }\end{array}$ & Power & & & \\
\hline Didemnids & 0.445 & 29 & 0.066 & 0.000 & 29 & na \\
\hline Diplosoma listerianum & 0.669 & 29 & 0.125 & 0.446 & 29 & 0.051 \\
\hline $\begin{array}{l}\text { Unknown solitary } \\
\text { ascidian recruits }\end{array}$ & 0.329 & 29 & 0.069 & 0.826 & 29 & 0.050 \\
\hline Amphicarpa meridiana & 0.211 & 29 & 0.052 & 0.357 & 29 & 0.051 \\
\hline Botryllus schlosseri & 0.566 & 29 & 0.110 & 0.545 & 29 & 0.119 \\
\hline Tricellaria porteri & 0.270 & 29 & 0.298 & 0.764 & 29 & 0.108 \\
\hline Parasmittina raigii & 0.163 & 29 & 0.101 & 0.127 & 29 & 0.058 \\
\hline Spirorbid polychaetes & 0.352 & 29 & 0.173 & 0.131 & 29 & 0.192 \\
\hline Serpulid polychaetes & 0.387 & 29 & 0.117 & 0.110 & 29 & 0.112 \\
\hline Yellow sponge & 0.492 & 29 & 0.218 & 0.086 & 29 & 0.110 \\
\hline Sandy sponge & 0.566 & 29 & 0.999 & 0.382 & 29 & 0.079 \\
\hline
\end{tabular}

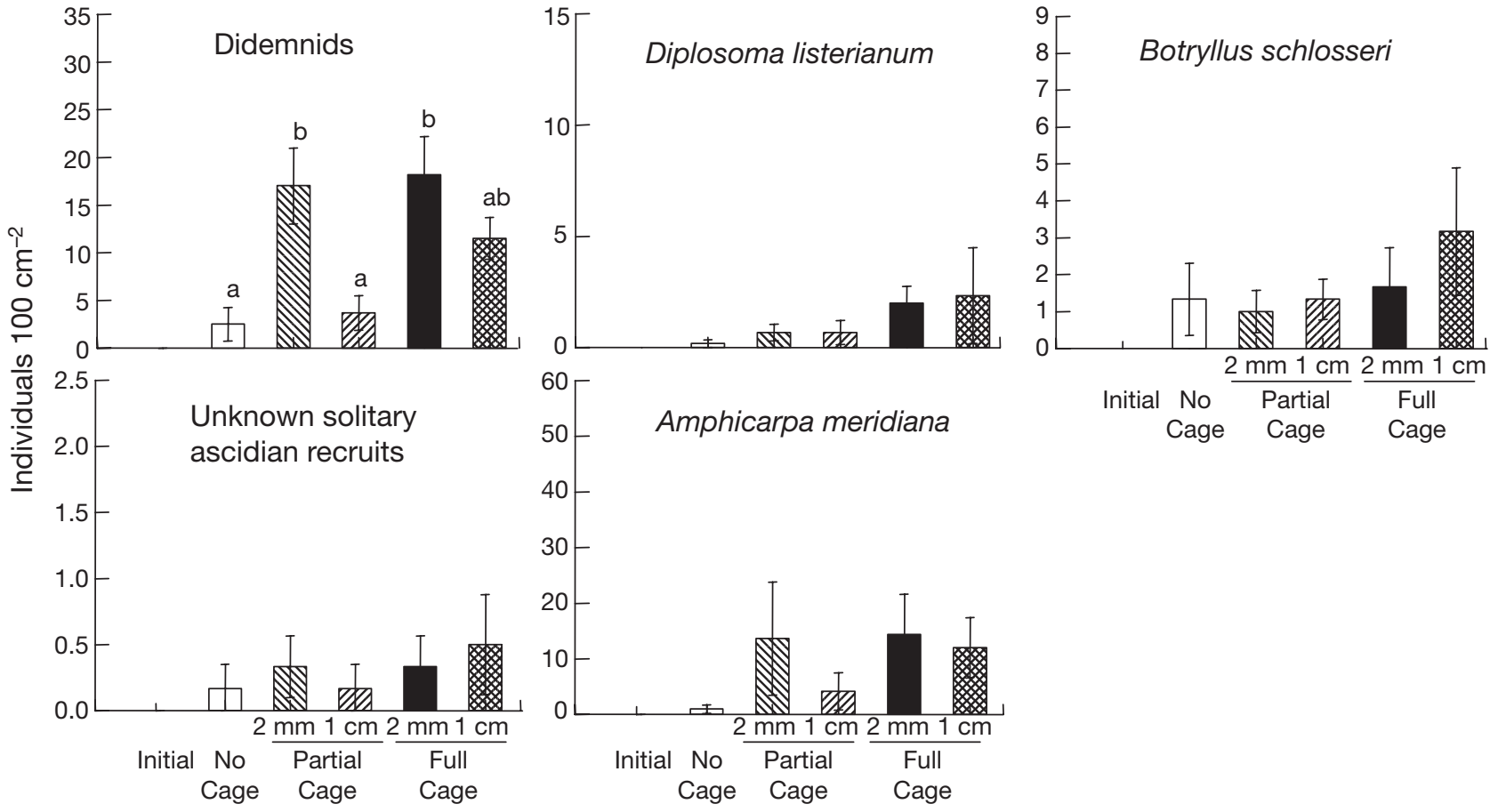

Fig. 10. Mean densities $( \pm \mathrm{SE})$ of ascidians present on plates at the end of $40 \mathrm{~d}$ predator exclusion experiments at Queenscliff. Letters occur where taxa showed significant differences in abundance between treatments (1-way ANOVA, $p<0.05)$. In these cases, treatments without letters in common are significantly different from each other (Tukey's HSD, $\mathrm{p} \leq 0.05$ ). Where there is no lettering above bars, treatment means are not significantly different (1-way ANOVA, p > 0.05) See legend to Fig. 1 for complete details

with effects caused by predation, with data suggesting that predators large enough to be excluded by a $2 \mathrm{~mm}$ mesh were responsible. Although we did not observe predation on didemnids directly, Russ (1980) found that monacanthid fish preyed on colonial ascidians (Distaplia viridis and Botrylloides nigrum) in communities at nearby Portsea in Port Phillip Bay, causing shifts in the structure of 4 and 7 mo old sessile communities. Similarly, Keough (1984a) suggested that monacanthids were important predators on didemnids growing on the shells of the bivalve Pinna bicolor in South Australia, and Keough \& Downes (1986) found that predators large enough to be excluded by $60 \mathrm{~mm}$ meshes, largely fish and urchins, were responsible for consider- 


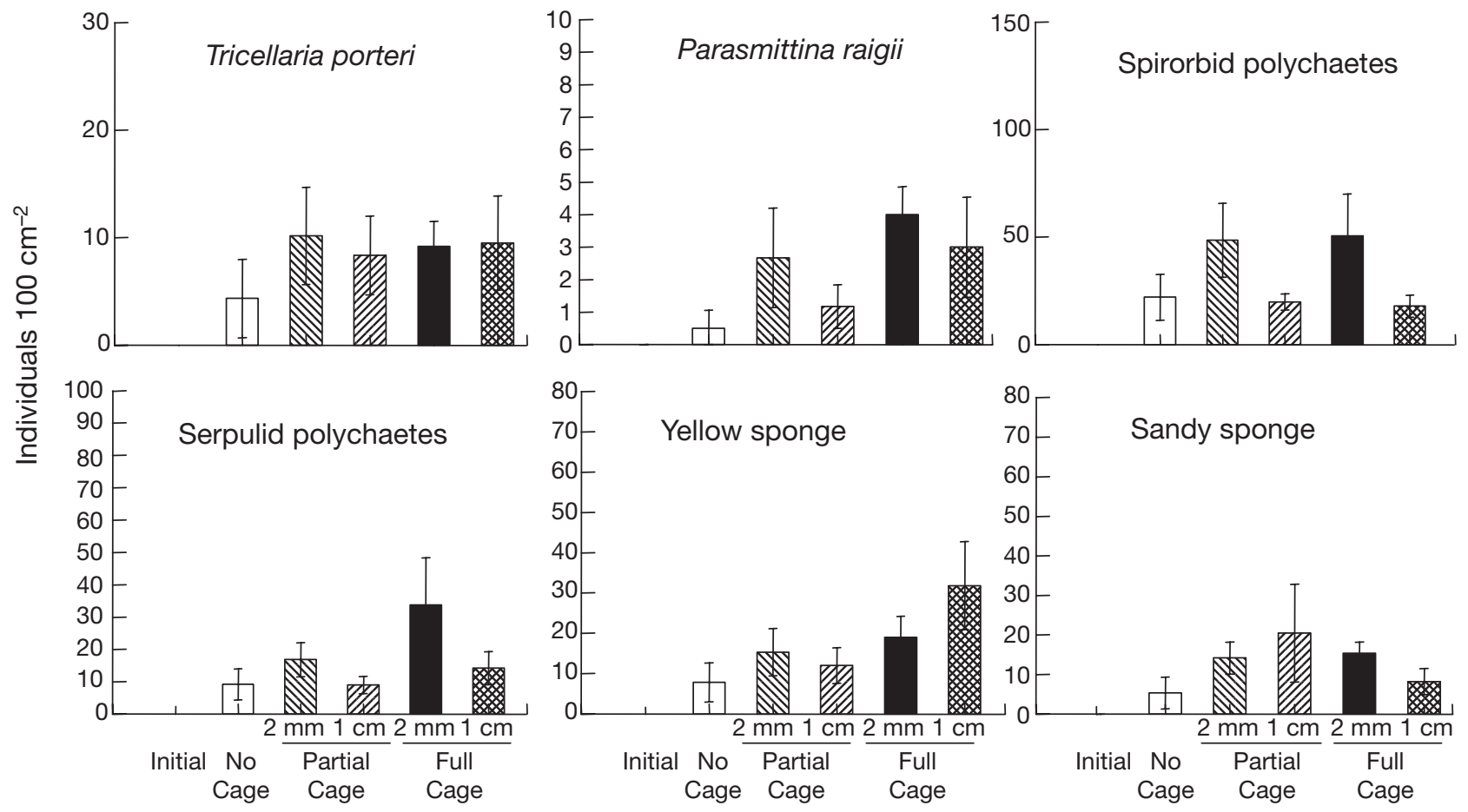

Fig. 11. Mean densities $( \pm \mathrm{SE})$ of common non-ascidian taxa present on plates at the end of $40 \mathrm{~d}$ predator exclusion experiments at Queenscliff. See legend to Fig. 1 for complete details

able didemnid mortality in California. A number of monacanthid species are commonly found in schools at Queenscliff Pier, and it is possible that they or other similar mobile predators consumed didemnid recruits. The large sea star Coscinasterias muricata was also observed on plates, but it seems unlikely that it was preying on small ascidian recruits. C. muricata is a voracious feeder on larger prey items including molluscs, crustaceans and moribund items, but rarely on ascidians (Keough \& Butler 1979). There is also a considerable size difference between C. muricata (arm length is $\sim 250 \mathrm{~mm}$ ) and recently settled didemnids ( $~ 800$ to $1000 \mu \mathrm{m})$ which, given the sea star's feeding behaviour, may also make it an unlikely predator on didemnid settlers. Changes in density were not seen for species like Botryllus schlosseri or Diplosoma listerianum, which are also likely to be preyed upon, and predation may have been due to smaller predators capable of targeting specific small prey. Caged plates were also protected from the action of disturbances like algal whiplash or bulldozing by mobile organisms (possibly C. muricatas) which are sources of mortality for sessile invertebrates, and may explain patterns of density for didemnids (Grant 1977, Hawkins 1983, Davis 1988). Other colonial ascidians on plates, such as D. listerianum (which also belongs to the Family Didemnidae) and B. schlosseri are just as likely to be vulnerable to disturbances as didemnids. Densities of these species did not differ among caged, partially caged or uncaged plates, so it is unlikely that disturbances were responsible for treatment differences in the densities of didemnids.

Although didemnids may have been preyed upon, there was little effect of predation on the overall structure of experimental communities at Queenscliff. In addition to the univariate analyses of individual taxa, Sams (2006) was unable to detect any broad differences in assemblages using MDS (multi-dimensional scaling ordination). At Queenscliff, the statistical power for all taxa in experiments was low, and moderate to high changes in density may have been undetected by 1-way ANOVA. Osman \& Whitlatch (1995, $1998,2004)$ found that predation during early postsettlement caused large changes in the density of key taxa, which resulted in the formation of markedly different communities. Such large effects would have been detected by experiments in this study. However, a number of the dominant taxa did not recruit in experiments at Queenscliff, and it is difficult to make generalizations regarding the effects that predation on early post-settlement stages may have on all species forming this sessile community.

At Williamstown, there was considerable recruitment throughout the experiments. For Botryllus schlosseri and Diplosoma listerianum, statistical power was consistently high throughout all predator exclu- 
sion experiments, whilst for Pyura stolonifera, Tricellaria porteri and didemnids it was strong in some experiments, but average in others. Changes in the densities of these species due to predation would have been detected in most experiments. These taxa are important contributors to sessile communities on artificial substrata at Williamstown, as they are major space occupiers, and it is likely that changes in their densities due to predation would be involved in any major change in community structure. Even though statistical power was not as high for some bryozoans or solitary ascidians, there was no consistently strong effect of predation on the recruitment rates of any of these taxa in 3 separate experiments at Williamstown, and any large changes (>100\%) would have been detected. Changes as large as those reported by Osman \& Whitlatch (1995, 1998, 2004) would have been detected reliably for almost all species. Ordinations (MDS, Sams 2006) also showed that the overall structure of communities was not affected by predation during early post-settlement. The combination of these results provides strong evidence that predation during early post-settlement did not greatly affect the recruitment of sessile invertebrates at Williamstown.

Whilst predation during early post-settlement exerted little control over the structure of communities at both Queenscliff and Williamstown, the reasons for these weak predator-prey interactions appear to be different at the 2 sites. In general, Queenscliff has low rates of recruitment. This was reflected by the low densities of most taxa during predator exclusion experiments. It is likely that these low recruitment rates were related to low larval settlement rather than an effect caused by predators. Although it is possible that predation during the $4 \mathrm{~d}$ pre-exposure period could influence recruitment, this seems unlikely, because recruitment remained low even after $40 \mathrm{~d}$ of predator exclusion, by which time any differences from $4 \mathrm{~d}$ preexposure should have vanished. Power (1998) also reported low recruitment rates at Queenscliff, and total recruitment is typically orders of magnitude lower than at Williamstown (M. Keough unpubl. data). Communities subject to low recruitment may be vulnerable to shifts in structure caused by predation during early post-settlement, as predators may easily consume the majority of new recruits. No small predators were found on either caged or uncaged plates. Fish were observed, but only rarely and did not appear to be present in the numbers reported by Russ (1980) at a nearby site. It may be that predators are not common at this site, providing a possible explanation for their low impact during early post-settlement for taxa at Queenscliff. Alternatively, if recruitment is infrequent, then the structure of sessile communities may be primarily determined by the competitive interactions between long-lived adults that reproduce asexually, rather than through the input of new individuals (Keough 1984b). Under such circumstances, predation during early post-settlement would have little influence on the structure of communities.

In contrast to Queenscliff, predators were commonly found on plates at Williamstown. Whilst some early recruits of these species were not excluded by cages, juveniles and adults, which are likely to have the highest consumption rates, are larger than $2 \times 2 \mathrm{~mm}$ and were effectively excluded by small mesh cages. No juveniles of any predatory species were found on plates caged with $2 \times 2 \mathrm{~mm}$ mesh size, and only 2 ind. of Goniodorus meracula and one of Polycera hedgpethi were observed on plates caged with $1 \times 1 \mathrm{~cm}$ mesh. The polycerid nudibranchs $P$. hedgpethi and Thecacera pennigera are both specialist predators on Bugula spp. (Rudman 1998). P. hedgpethi consumes large amounts of $B$. neritina colonies in a short time (Bone \& Keough 2005) and may be able to influence the recruitment of $B$. neritina into communities by preying on new settled individuals. Whilst $P$. hedgpethi was occasionally observed feeding on recently settled Bugula recruits, it was generally found on large bushy colonies, and it may have a preference for older colonies as prey. T. pennigera was never observed feeding. G. meracula, the most common predator found on plates at Williamstown, is found on the colonial ascidian Botryllus schlosseri and appears to prey solely on this ascidian (Burn 1989). G. meracula, like $P$. hedgpethi, appeared to prefer older colonies and was never observed feeding on newly settled ascidians. When it was feeding, it generally only ate small holes into larger colonies, leaving the majority of the colony intact.

Recruitment of a number of species was high during experiments at Williamstown, and experiments at both sites were run during periods when settlement and recruitment were at high levels. When settlement and recruitment levels are high, prey species may swamp predators. This appears to be the case for Botryllus schlosseri, which settled in moderate densities but, given the apparently low consumption rates of Goniodorus meracula, may have been able to settle in higher densities than could be consumed. Carroll (1996) found that predation on newly recruited barnacles by whelks and sea stars caused a decrease in the number of barnacles recruiting in a year with low settler densities, but had no effect in 2 yr with high settler densities. A similar effect may have been occurring at Williamstown where settlement rates for a number of taxa were very high. At times when settlement is lower, predation may have a stronger impact on recruitment success and be more likely to influence community structure. 
Whilst there may be numerous explanations for the weak effect of predation on early post-settlement sessile invertebrates at Williamstown and Queenscliff, the most obvious difference between these communities and communities such as those found in New England, where predation during early postsettlement was shown to exert strong effects on the structure of communities, is the abundance of predators. Osman \& Whitlatch (2004) found that a number of generalist predators (fish and gastropods) acting at different trophic levels and on different size classes of prey were responsible for causing and maintaining changes in community structure. They also reported $>400$ ind. of the predatory gastropod Mitrella lunata occurring on experimental pilings $(75 \times 28 \mathrm{~cm}$ PVC pipes). No more than 10 ind. of all predators combined were found per plate $(11 \times 11 \mathrm{~cm})$ from Williamstown, whilst predators appeared to be rare or absent at Queenscliff. At Williamstown, predators only fed on one or a few species, and either did not prey on early recruits of major space occupiers or, where they did, were not voracious. Consequently, they may be less likely to exert strong, community level effects than voracious predators with a generalist diet.

Hall et al. (1990) suggested that the incidence of weak predator-prey interactions is often underemphasised in the ecological literature, which may lead to a general misconception regarding the importance of predators in all communities. It is becoming increasingly apparent that predators do not always play major roles in shaping community structure and that the effects of predation may be location and/or time specific (Keough 1984a, Summerson \& Peterson 1984, Fairweather \& Underwood 1991, Menge et al. 1994). This study demonstrates that predation during early post-settlement also may have varying degrees of importance for different sessile communities. Whilst predation during early post-settlement is a major process shaping the structure of sessile invertebrate communities in New England, it seems to have little influence in the communities studied in Port Phillip Bay. Other studies have also reported weak effects of predation during early post-settlement for sessile species, suggesting that weak predator-prey interactions during early post-settlement may not be unique to the communities focused on in this study (Petraitis 1990, 1991, Carroll 1996).

Acknowledgements. We thank A. O'Brien, K. Blackman, D. Semmens, E. Bone and E. Broughton for their diving support and assistance with field work. We thank B. Loughman for assistance in the field and laboratory. We also thank Parks Victoria for allowing us the use of Workshops Pier, Williamstown, and Queenscliff Pier, Queenscliff.

\section{LITERATURE CITED}

Barkai A, Branch GM (1988) The influence of predation and substratal complexity on recruitment onto settlement plates: a test of the theory of alternative states. J Exp Mar Biol Ecol 124:215-237

Bone EK, Keough MJ (2005) Response to damage in an arborescent bryozoan: effects of injury location. J Exp Mar Biol Ecol 324:127-140

Burn RF (1989) Opisthobranchs. In: Shepherd SA, Thomas IM (eds) Marine invertebrates of southern Australia, part II. South Australian Government Printing Division, Adelaide, South Australia, p 725-788

Carroll ML (1996) Barnacle population dynamics and recruitment regulation in southcentral Alaska. J Exp Mar Biol Ecol 199:285-302

Davis AR (1988) Colony regeneration following damage and size dependent mortality in the Australian ascidian Podclavellina moluccensis Sluiter. J Exp Mar Biol Ecol 123: 269-285

Duffy JE, Harvilicz AM (2001) Species-specific impacts of grazing amphipods in an eelgrass bed community. Mar Ecol Prog Ser 223:201-211

Fairweather PG, Underwood AJ (1991) Experimental removals of a rocky intertidal predator-variations within 2 habitats in the effect on prey. J Exp Mar Biol Ecol 154:29-75

Gosselin LA, Qian PY (1996) Early post-settlement mortality of an intertidal barnacle: a critical period for survival. Mar Ecol Prog Ser 135:69-75

Gosselin LA, Qian PY (1997) Juvenile mortality in benthic marine invertebrates. Mar Ecol Prog Ser 146:265-282

Grant WS (1977) High intertidal community organization on a rocky headland in Maine, USA. Mar Biol 44:15-25

Hall SJ, Raffaelli D, Turrell WR (1990) Predator-caging experiments in marine systems: a re-examination of their value. Am Nat 136:657-652

Hawkins SJ (1983) Interactions of Patella and macroalgae with settling Semibalanus balanoides (L.). J Exp Mar Biol Ecol 71:55-72

Hewitt CL, Campbell ML, Thresher RE, Martin RB and 15 others (2004) Introduced and cryptogenic species in Port Phillip Bay, Victoria, Australia. Mar Biol 144:183-202

Hunt HL, Scheibling RE (1997) Role of early post settlement mortality in recruitment of benthic marine invertebrates. Mar Ecol Prog Ser 155:269-301

Hurlbut CJ (1991) The effects of larval abundance, settlement and juvenile mortality on the depth distribution of a colonial ascidian. J Exp Mar Biol Ecol 150:183-202

Keough MJ (1984a) Dynamics of the epifauna of the bivalve Pinna bicolor: interactions among recruitment, competition and predation. Ecology 65:677-688.

Keough MJ (1984b) Effects of patch size on the abundance of sessile marine invertebrates. Ecology 65:423-427

Keough MJ, Butler AJ (1979) The role of asteroid predators in the organization of a sessile community on pier pilings. Mar Biol 51:167-177

Keough MJ, Downes BJ (1982) Recruitment of marine invertebrates: the role of active larval choices and early mortality. Oecologia 54:348-352

Keough MJ, Downes BJ (1986) Effects of settlement and post settlement mortality on the distribution of the ascidian Trididemnum opacum. Mar Ecol Prog Ser 33:279-285

Menge BA (1991) Relative importance of recruitment and other causes of variation in rocky intertidal community structure. J Exp Mar Biol Ecol 146:69-100

Menge BA, Berlow EL, Blanchette CA, Navarrete SA, Yamada SB (1994) The keystone species concept - varia- 
tion in interaction strength in a rocky intertidal habitat. Ecol Monogr 64:249-286

Moreno CA (1995) Macroalgae as a refuge from predation for recruits of the mussel Choromytelis chorus (Milina 1782) in southern Chile. J Exp Mar Biol Ecol 191:181-193

Morgan SG (2001) The larval ecology of marine communities. In: Bertness MD, Gaines SD, Hay ME (eds) Marine community ecology. Sinauer Associates, Sunderland, p 159-181

Osman RW, Whitlatch RB (1995) Predation on early ontogenetic life stages and its effect on recruitment into a marine epifaunal community. Mar Ecol Prog Ser 117:111-126

Osman RW, Whitlatch RB (1998) Local control of recruitment in an epifaunal community and the consequences to colonization processes. Hydrobiologia 376:113-123

Osman RW, Whitlatch RB (2004) The control and development of an epifaunal community by predation on recruits. J Exp Mar Biol Ecol 311:117-145

Osman RW, Whitlatch RB, Malatesta RJ (1992) Potential role of micro-predators in determining recruitment into a marine community. Mar Ecol Prog Ser 83:35-43

Petraitis PS (1990) Direct and indirect effects of predation, herbivory, and surface rugosity on mussel recruitment. Oecologia 83:405-413

Petraitus PS (1991) Recruitment of the mussel Mytelis edulis L. on sheltered and exposed shores in Maine, USA. J Exp Mar Biol Ecol 147:65-80

Power B (1998) The dispersal distance of sessile benthic

Editorial responsibility: Pei-Yuan Qian (Contributing Editor), Kowloon, Hong Kong SAR marine invertebrates, its predictors and consequences. $\mathrm{PhD}$ thesis, University of Melbourne, Parkville

Rudman WD (1998) Suborder Aeolidina. In: Beesley PL, Ross GJB, Wells A (eds) Mollusca: the southern synthesis. CSIRO Publishing, Melbourne

Russ GR (1980) Effects of predation by fishes, competition and structural complexity of the substratum on the development of a marine epifaunal community. J Exp Mar Biol Ecol 42:55-69

Sams MA (2006) Predation during early post settlement: an important process shaping marine sessile communities? BSc (Hons) thesis, University of Melbourne, Parkville

Sih A, Crowley P, McPeek M, Petranka J, Stohmeier K (1985) Predation, competition and prey communities - a review of field experiments. Ann Rev Ecol Syst 16:269-311

Summerson HC, Peterson CH (1984) Role of predation in organizing benthic communities of a temperate sea-grass bed. Mar Ecol Prog Ser 15:63-77

Sutherland JP (1974) Multiple stable points in natural communities. Am Nat 108:859-873

Young CM, Chia FS (1984) Microhabitat associated variability in survival and growth of subtidal solitary ascidians during the first 21 days after settlement. Mar Biol 81:61-6

Zamorano JH, Moreno CA, Duarte WE (1995) Post-settlement mortality in Phragmatopoma virgini (Polychaeta: Sabellariidae) at the Mehuin Marine Reserve, Chile. Mar Ecol Prog Ser 127:149-155

Submitted: September 21, 2006; Accepted: April 16, 2007

Proofs received from author(s): September 18, 2007 